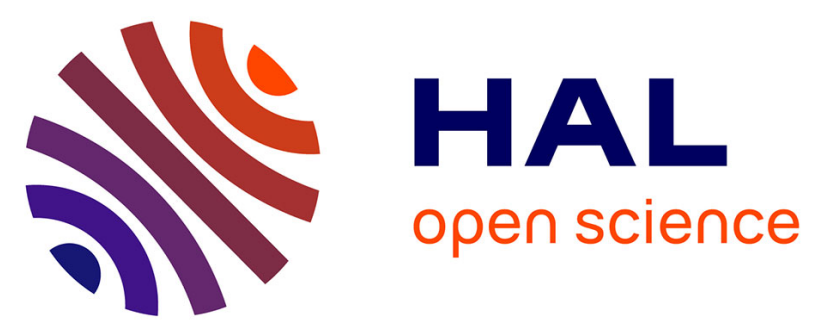

\title{
Consignment contracts with cooperative programs and price discount mechanisms in a dynamic supply chain
}

Alessandra Buratto, Rudy Cesaretto, Pietro de Giovanni

\section{To cite this version:}

Alessandra Buratto, Rudy Cesaretto, Pietro de Giovanni. Consignment contracts with cooperative programs and price discount mechanisms in a dynamic supply chain. International Journal of Production Economics, 2019, 218, pp.72 - 82. 10.1016/j.ijpe.2019.04.027 . hal-03484602

\section{HAL Id: hal-03484602 \\ https://hal.science/hal-03484602}

Submitted on 20 Dec 2021

HAL is a multi-disciplinary open access archive for the deposit and dissemination of scientific research documents, whether they are published or not. The documents may come from teaching and research institutions in France or abroad, or from public or private research centers.
L'archive ouverte pluridisciplinaire HAL, est destinée au dépôt et à la diffusion de documents scientifiques de niveau recherche, publiés ou non, émanant des établissements d'enseignement et de recherche français ou étrangers, des laboratoires publics ou privés.

\section{다)(1) $(5$}

Distributed under a Creative Commons Attribution - NonCommerciall 4.0 International 
Version of Record: https://www.sciencedirect.com/science/article/pii/S0925527319301562

Manuscript_330932964e3af555f4a3c3b34ec50259

\title{
Consignment contracts with cooperative programs and price discount mechanisms in a dynamic supply chain
}

\author{
Alessandra Buratto \\ University of Padova, Department of Mathematics, via Trieste 63, I-35121 Padova, Italy \\ Rudy Cesaretto \\ University of Padova, Padova, Italy \\ Pietro De Giovanni ${ }^{1}$
}

ESSEC Business School, Department of Operations Management, av. B. Hirsch 3, 95021 Cergy, Paris, France

\footnotetext{
${ }^{1}$ Corresponding author.

Email: pietro.degiovanni@essec.edu

Phone: 0033688185024
} 


\title{
Consignment contracts with cooperative programs and price discount mechanisms in a dynamic supply chain
}

20th April 2019

\begin{abstract}
This paper investigates whether a supply chain can achieve coordination by implementing two mechanisms: a cooperative advertising program and a price discount mechanism. We start by analyzing a consignment contract with a revenue-sharing agreement in which a manufacturer decides both the price and the quality investment while the retailer sets the store advertising efforts. The manufacturer is the brand owner and increases the goodwill through quality and pricing. We solve three dynamic games, in which the manufacturer is the Stackelberg leader, and compare the related solutions. We discover that the manufacturer, as chain leader, will always propose the adoption of a coordination mechanism. When the manufacturer opts for a cooperative program, the retailer is always economically better off; thus, a cooperative program is always profit-Pareto-improving. When the manufacturer opts for a price discount mechanism, the retailer is always economically worse-off because the discount applies only to her margins. Nevertheless, the price discount mechanism is profit-Pareto-improving in the case of high production cost: The price discount allows for considerably reducing the retail price, which translates to a substantial increase in demand. In all other cases, the retailer sets zero price discount, thus preferring a non-coordinated framework.
\end{abstract}

Keywords: Pricing, Advertising, Marketing-Operations interface, Game theory.

\section{Introduction}

The topic of coordination in supply chains has received wide attention in past years. Coordination refers to the implementation of a mechanism (e.g., a contract) that allows all firms within a chain to be economically better off (Cachon, 2003). Then, coordination seeks to push firms to maximize the overall supply chain profits rather than focusing on single outcomes (Desai et al., 2001). Ingene et al. (2014) define coordination as the policy through which a decentralized chain can mimic the vertical integrated solution. The literature that investigates the mechanisms needed to successfully achieve coordination divides them into two groups: non-price-based and price-based mechanisms. Non-price-based coordination mechanisms refer to the establishment of contracts based on operational issues such as inventory (e.g., Achabal et al., 2000; De Giovanni et al., 2019), operating costs (e.g., Cho and Gerchak, 2005), advertising (e.g., Jørgensen and Zaccour, 2014; Karray et al., 2017), returns (e.g., De Giovanni, 2015), and promotions (e.g., Karray, 2006). For example, Achabal et al. (2000) demonstrate the suitability of a Vendor Management Inventory contract for coordinating a chain since it allows 
retailers to better manage their inventory and to better adjust their production decisions. Desai and Srinivasan (1996) use a quantity discount and a slotting allowance mechanism to coordinate a channel in which franchise fees and royalties are aggregated. Buratto and Zaccour (2009), Buratto (2012, 2013), and Buratto et al. (2015) consider different coordination strategies for a licensing contract with possible participation of the licensor in the licensee's advertising expenditures. Tsay and Lovejoy (1999) study quantity-flexibility contracts in a multiperiod setting with demand forecast updates. Jørgensen et al. (2000) show that an inter-temporal support program allows a manufacturer to direct the retailer's advertising efforts in certain ways. De Giovanni (2016b) conducts a qualitative analysis by exploring 23 manufacturing companies and shows that the contracts most frequently used for coordinating a supply chain are quantity discount and quantity flexibility. Also, Prekker and De Giovanni (2019) carry out a comparative case study analysis on five companies belonging to the same supply chain, discovering that the mechanisms most frequently used for coordination are the Intelletual Property-based contracts.

A second stream of research focuses on pricing-based contracts in which coordination is sought by involving both the pricing strategies and the sharing mechanisms. The pricing-based literature has been largely developed through the analysis of the wholesale price contract (WPC) and its comparison with the revenue-sharing contract (RSC). Under a WPC, the supply chain seldom achieves coordination because several uncontrollable factors, such as the retailer's size, cost, and degree of competition, diminish its effectiveness (Ingene and Parry, 2000). The literature mainly compares the WPC to the RSC since the latter can mitigate the double marginalization. The seminal works by Cachon (2003) and Cachon and Lariviere (2005) offer clear positioning regarding the benefits that an RSC provides compared to a WPC. Although these price-based mechanisms (WPC and RSC) have been extensively investigated and compared, both focus on the case in which the retailer is the only player setting the final market price. Although this setting applies in several instances (see De Giovanni (2016b) for a comprehensive analysis of the sectors using such contracts), firms move to a different type of business model, according to which the manufacturer defines the selling prices while the retailer just sticks with those prices. For example, Apple's and Samsung's devices are sold at the same prices all over the world regardless of the retailer selling the products to the market. Dealers in the automotive sectors sell cars at the same starting price while leaving small margins to play with. In the food industry, Parmalat prints the price of fresh milk on the bottle labels; thus, retailers have no chance to sell it at a lower price. In the fashion industry, producers like Armani, Versace, Boss, and Marella fix the prices at which retailers must sell the products, even independent of the country in which the retailer is located. The literature on supply chain and distribution channel has mainly focused on settings in which the downstream firm (most likely the retailer) decides the price. This links to the earlier mentioned price-based coordination literature, which mainly compares the wholesale price contract to the revenue-sharing contract to solve the double marginalization issue and achieve coordination. In contrast, our model applies to a supply chain (SC) setting in which the upstream firm decides the price, along with the quality efforts. Specifically, we seek to contribute to the domain of price-based coordination mechanisms in which manufacturers set the selling price. In these circumstances, neither a WPC nor an RSC applies if aiming at coordination. Rather, we investigate the supply chain relationships by using a consignment contract with sharing agreements. 
A consignment contract consists of a set of agreements according to which the manufacturer supplies the products to be sold to the retailer's store, the retailer sells these products, and the two firms share the profits according to a sharing rule negotiated ex-ante and embedded in the consignment contract (De Giovanni, 2016a). In doing so, all possible issues linked to double marginalization disappear. Consignment contracts are currently used in various contexts, especially in online marketplaces such as Amazon.com ( $\mathrm{Li}$ and Hua, 2008). In most cases, the consignment arrangement allows the firms to negotiate the revenue-sharing percentage before entering into any type of relationship and then the strategies can be set accordingly (Wang et al., 2004; Li and Hua, 2008; Li et al., 2009). Li and Hua (2008) model several types of demand functions to show the effectiveness of a consignment contract with revenue-sharing. They demonstrate the robustness of this mechanism in coordinating the supply chain. In the same vein, Wang et al. (2004) investigate the suitability of a consignment contract with sharing agreements and find that the share levels and demand price elasticity determine the convenience of using such a coordination mechanism. Adida and Ratisoontorn (2011) investigate two variants of consignment contracts, one with a revenue-sharing rule and one without. They show that firms within a supply chain can have divergent preferences: An upstream firm targets a consignment with sharing agreements only when the down stream firm provides a sufficiently large level of differentiation; in contrast, the downstream firm will always prefer a consignment without a sharing agreements. Battini et al. (2010) demonstrate the power of a consignment contract in coordinating a chain even in the presence of adverse situations, such as space constraints, obsolescence risks, demand variability, and shortage risks. Li et al. (2009) analyze the consignment contract under a specific demand structure and show that the mechanism leads to coordination only when it also embeds constraints linked to the demand function. Avinadav et al. (2015a, 2015b, 2017) use a consignment contract to investigate coordination in a supply chain composed of app developers in the chain upstream and app sellers in the chain downstream. They show the conditions under which a consignment contract can coordinate the chain. Other papers, such as Dong and Xu (2002), Choi et al.(2004), De Giovanni and Roselli (2012), and Cachon (2004), show that the consignment contract cannot perfectly coordinate the decentralized supply chain, thus leaving an open question regarding its real suitability. We insert our contribution in this research frame to investigate the supply chain members' performance under a consignment contract and search for additional coordination mechanisms to increase its suitability.

We use a dynamic approach to mimic the supply chain model in the aforementioned sectors. In these cases, the manufacturer is so powerful (brand's owner) that either the retailer accepts selling the products at the price the manufacturer fixes or the manufacturer searches for other retailers. The manufacturer's brand is so popular that it is in the retailer's best interest to work with the brands because consumers are attracted by the presence of these brands in stores. For example, Mediastore in Italy and Darty in France are retailers of electronics products. They sell Apple products at the same price, which is exclusively decided by Apple and leads to a higher number of visits due to the presence of Apple products. In these instances, manufacturers build up their brands over time by means of several types of strategies. Nerlove and Arrow (1962) introduce the variable "goodwill" to describe the effects of advertising on sales. Most of the dynamic games papers use the dynamic equations proposed by Nerlove and Arrow to explore the implications of advertising (Jørgensen and Zaccour, 2014) or conformance quality (De Giovanni, 2019) on brand value. Differently, we characterize a goodwill 
stock that evolves according to both quality improvements and pricing. Quality improvements are considered technological upgrades and innovative solutions that firms propose in the market (e.g., i-Phone 6 vs i-Phone 7 ) and they clearly play an important role in building up the stock of goodwill. De Giovanni (2011) models a dynamic game in which quality improvements increase the goodwill stock while the manufacturer manages the trade-off between investing in quality and supporting the retailer's advertising efforts to achieve satisfactory levels of goodwill. We adopt a similar approach, where the manufacturer's quality improvement investments play an important role in the brand value. This is quite convincing when thinking about the aforementioned firms (e.g., Apple, Armani, Samsung) as consumers somehow expect these firms to make high-quality (e.g., high-tech) products. In addition, the price plays a very important role in signaling the quality embedded in the products. Martin-Herran et al. (2014) show that higher prices are not detrimental to firms' profits if those prices are a signal of quality. This concept especially applies in the supply chain framework that we seek to model. For example, in 2016, Apple launched an i-Phone 7 with a release price of $699 \$$ in UK. Consumers were well aware of this launch; thus, if the selling price displayed for an i-Phone 7 was $\$ 299$, consumers would clearly feel that the product was a fake. Therefore, for sectors like electronics, fashion and automotive consumers expect products to have a certain (high) price, such that they comfortably trust the brand and the goods to which they are exposed. Therefore, we model a goodwill that depends on both quality improvements and pricing strategies. In our model, the retailer decides on her store advertising investments to increase sales. Again, we have in mind the supply chain model of Mediatore and Darty, in which the retailers advertise to attract more consumers (e.g., advertising that brands are available in the store) but these efforts do not influence the manufacturer's brand value. For example, if Mediastore and Darty do not advertise at all, consumers are still very much aware of Apple's brand value and its quality (technological) progress. Moreover, even if these retailers invest heavily in advertising, consumers do not change the value they assign to the Apple brand. Thus, the retailers' store advertising does not influence the manufacturer's brand. Overall, compared to the aforementioned literature, our model contributes in three ways:

1. We characterize a consignment contract with a sharing agreement in a dynamic supply chain, while the extant research mainly deals with static supply chain models with consignment agreements.

2. This is the first paper to model the goodwill stock as depending on both the pricing and the quality; the literature has mainly focused on advertising and promotion strategies influencing goodwill while the sole contribution by Martin-Herran et al. (2014) uses pricing and quality as tools to enhance consumers' perceived quality.

3. We model the manufacturer's stock of goodwill as independent of the retailer's store advertising efforts, while the dynamic games literature focuses on models in which retailers can influence the manufacturer's brands by advertising and/or promotion investments.

Since we use the definition of SC coordination given by Cachon (2003), we search for an instrument that can both complement the consignment contract earlier proposed and be profit-Pareto-improving. Manufacturers can complement a consignment contract with a cooperative advertising program by paying a fraction of the retailer's advertising expenses (Kali, 1998). Israeli et al. (2016) list a variety of sectors in which cooperative programs are used successfully, including electronics (e.g., Sony, Bose, Samsung), cameras (e.g., Olympus), video games (e.g., Nintendo), housewares (e.g., 
Viking, Sub-Zero), sporting goods (e.g., Callaway, TaylorMade), computers (e.g., Hewlett-Packard (HP)), toys (e.g., Activision Blizzard, LeapFrog), marine equipment (e.g., JL Marine), motor sports (e.g., GPR Stabilizer), and plumbing (e.g., Brasstech). Most of the papers about cooperative advertising have explored the implications of using such programs in supply chains and distribution channels to solve marketing problems (Jørgensen et al., 2000, 2003; Karray and Zaccour, 2005; He et al., 2009; Karray et al., 2017b). These models assume that strategies subject to cooperative advertising programs affect the product's brand image (goodwill), which exerts a positive influence on sales and then profits. Cooperative advertising programs have largely been investigated in the literature of distribution channels and supply chain management. In general, when cooperative advertising programs are applied to simple chains, the retailer's advertising efforts tend to be higher such that consumers become less sensitive to price increase. A cooperative advertising program can be an effective coordination mechanism for bilateral monopolistic channels (e.g., Jørgensen et al., 2000; Yue et al., 2006; Karray and Zaccour, 2006; Yang et al., 2013; He et al., 2009; Karray, 2013; Martín-Herrán and Sigué, 2016). Therefore, we investigate the effectiveness of a cooperative program with our supply chain. Our research differs from the aforementioned literature in three ways:

1. We investigate the effectiveness of a cooperative program when the price is set by the manufacturer; the extant research has mainly focused on frameworks in which the cooperative program is implemented when the retailer fixes the price.

2. The cooperative advertising program does not influence the state, as store advertising efforts do not influence the goodwill stock, which instead depends on the quality and the pricing strategy; the dynamic games literature has focused on cases when a support program is applied to a control that influences the state.

3. In this paper, firms can complement a consignment contract with a cooperative program; however, most of the extant research has focused on cooperative advertising programs in which the supply chain uses either a wholesale price contract (e.g., Chernonog and Avinadav 2017) or a revenue-sharing contract (e.g., Jørgensen and Zaccour, 2004, 2014).

Along with a cooperative advertising program, a supply chain can complement a consignment contract with a price discount program. The latter aims at giving some freedom to retailers, who can still affect the retail price by applying discounts (Calvani and Berg, 1984). Although the manufacturers set the price, the retailer can still control it through the discount. The price discount program can be highly successful for increasing sales (Mathewson and Winter, 1998). Modak et al. (2015) demonstrate that a price discount program does not coordinate a supply chain, unless a two-part tariff along with contractual bargaining complement the contract. Yue et al. (2006) show that a price discount is beneficial when the manufacturer practices the price discount while contractual bargaining and collaborative advertising programs exist at both the national and local levels. Yue et al. (2013) extend their previous work to the case in which both a manufacturer and a retailer can apply price discounts, showing that a price discount does not coordinate a supply chain even in the presence of a local advertising support program. Puppe and Rosenkranz (2001) emphasize that the price discount mechanism should be used parsimoniously because there is a "reference price" effect as consumers form a mental evaluation of the price consumers want to pay for a given product. Buehler and Gärtner (2013) justify the use of a price discount by arguing that manufacturers have a better understanding of the production cost, so they have more information 
on how to set the optimal price. Hence, they show that this mechanism can be beneficial in a dynamic (repetitive) context because retailers learn more about the manufacturers' operational performance. Della Bitta et al. (1981) demonstrate that the price discount can have a very tricky effect: If the discount is too low, consumers can perceive it to be insufficient to justify a purchase; in contrast, if it is too high, consumers can perceive a lack of trust. The latter is especially true when the price is a signal of product quality (Della Bitta et al., 1981). Also in this case, we characterize a price discount model that differs from those in the literature in three ways:

1. We model price discount in a dynamic games framework in which the discount deteriorates the manufacturer's goodwill. This is the only case in which the retailer influences the manufacturer's goodwill.

2. Our model considers the effects of a price discount mechanism within a consignment contract, while previous research has characterized theoretical models based on other types of contracts (e.g., wholesale price contracts).

3. The retailer is fully responsible for the decisions surrounding the price discount mechanism, while the manufacturer's margins are not influenced.

We start from the analysis of a benchmark scenario, namely, the consignment contract with a sharing agreement, in which the manufacturer decides the quality improvement investments along with the final product price while the retailer sets the store advertising efforts. Retailers are extremely proud and interested in selling high-quality products as the presence of certain brands in their store attracts more consumers and increases consumers' visits. Thus, the retailer sets the advertising efforts to increase the consumers attracted to their store but without influencing the goodwill. We evaluate whether a consignment contract with a sharing agreement can be complemented by a cooperative advertising program or a price discount contract to make all firms within the supply chain economically better off.

The paper is organized as follows. Section 2 introduces the models and all related assumptions and Section 3 displays the related equilibria. Section 4 compares the solution of the games while Section 5 concludes.

\section{The models}

We consider a supply chain composed of one manufacturer, denoted by $M$, and one retailer, denoted by $R$. We assume that $M$ has infinite production capacity and that $R$ does not sell any other competing products to the market. $M$ is the chain leader and decides the selling price, $p(t) \geq 0$, along with the quality improvement (e.g., product innovation and technology development) efforts $Q(t) \geq 0$. M's strategies contribute to the product's stock of goodwill, $G(t)$, which can be interpreted as the consumers' awareness of $M$ 's brand as well as the value that consumers associate with it. We model a particular type of supply chain in which $M$ is recognized as a leader in the market and has a high brand value.

We formalize the problem in terms of a Stackelberg differential game, where $M$ acts as leader and $R$ as follower. The state equation that explains the accumulation of goodwill over time takes the following form:

$$
\dot{G}(t)=a Q(t)+b p(t)-\delta G(t) .
$$

The interpretation of equation (1) is as follows: $M$ invests in quality improvements at a rate $Q(t)$, which reflects the quality 
improvements' contribution to the accumulation of brand value that consumers associate with $M$ 's business. The term $a$ $(>0)$ is $M$ 's quality efficiency and represents the increase in the stock $G(t)$ any time $M$ invests in quality. Furthermore, the selling price $p(t)$ is a signal of product quality that also contributes to the accumulation of $G(t)$ via the parameter $b(>0)$. The decay term $-\delta G(t)$ characterizes the natural decrease of goodwill stock (Jorgensen, 2012; Dockner, 2000). The form of (1) guarantees positive goodwill at any given moment in time.

$M$ 's products are sold by $R$, who has (at least in principle) no right to sell them at a price different from the one set by $M$. Thus, she decides to make store advertising efforts, $A(t)$, to attract more consumers to her store and hence to increase demand. In particular, the demand function will take the following form:

$$
S(p(t), A(t), G(t))=\alpha-\beta p(t)+\gamma G(t)+\theta A(t)
$$

where $\alpha(>0)$ is the market potential, $\beta(>0)$ is consumers' sensitivity to price, $\gamma(>0)$ is the amount of consumers attracted to the store who purchase goods because $M$ 's products are on display, and $\theta(>0)$ is consumers' sensitivity to $R$ 's store advertising efforts. The idea behind Eq. (2) is that some consumers visit $R$ because she sells products of $M$ 's brand. This flow of consumers is captured through $\gamma$. At the same time, other consumers visit $R$ 's store and purchase $M$ 's products thanks to $R$ 's adverting efforts. This is also consistent with Apple's supply channel behavior. Apple sells through retailers such as Mediastore and Darty; consumers visit these stores either because the stores sell Apple products (e.g., consumers visit a store because they want to purchase Apple's products and know that Mediastore and Darty display Apple products on their shelves) or because they are attracted by $R$ 's store advertising. Nevertheless, Mediastore and Darty are independent retailers and do not contribute to Apple's brand value: Apple constructs its reputation independent of $R$ 's store advertising efforts. Consequently, $A$ does not appear in (1).

To replicate the Apple and Mediastore distribution channels and supply chains, we model the selling price as within $M$ 's control, for which $R$ has no influence in principle. This is de facto what happens for Apple's products; the selling price is the same in all independent retailers that a consumer visits. Thus, $R$ just sells $M$ 's products at the price set by $M$. The firms use a consignment contract to manage the financial flows, according to which $R$ retains a certain fraction, $\phi \in(0,1)$, of the selling price, such that her marginal profits are given by $\pi_{R}=p(t) \phi$. The other part is retained by $M$, whose marginal profits take the form $\pi_{M}=p(t)(1-\phi)-c_{M}$ where $c_{M} \quad(>0)$ is the marginal production cost. Consequently, $M$ fixes the price by ensuring that $p(t)(1-\phi)>c_{M}$. M's quality efforts and $R$ 's store advertising efforts take a quadratic and convex form, specifically $C_{Q}=\mu_{M}[Q(t)]^{2} / 2$ and $C_{A_{R}}=\mu_{R}[A(t)]^{2} / 2$, respectively, where $\mu_{M}$ and $\mu_{R}$ are positive constants.

We start our analysis from the benchmark scenario in which $M$ sets the retail price, $p(t)$, and the quality efforts, $Q(t)$, whereas $R$ fixes the store advertising efforts. We denote the benchmark scenario by " $B$ " and the demand function $S^{B}$ 
takes the form of (2). The consignment scenario considers the following players' payoffs:

$$
\begin{aligned}
\max _{p^{B}(t), Q^{B}(t) \geq 0} J_{M}^{B} & =\int_{0}^{+\infty} e^{-r t}\left\{S^{B}\left[p^{B}(t)(1-\phi)-c_{M}\right]-\frac{\mu_{M} Q^{B}(t)^{2}}{2}\right\} d t \\
\max _{A^{B}(t) \geq 0} J_{R}^{B} & =\int_{0}^{+\infty} e^{-r t}\left\{S^{B} p^{B}(t) \phi-\frac{\mu_{R} A^{B}(t)^{2}}{2}\right\} d t
\end{aligned}
$$

subject to (1), assuming that the initial goodwill level is $G(0)=G_{0}$. Both firms show profit-maximization behavior and play a dynamic game under an infinite time horizon in which $r$ is the common discount factor.

This benchmark game corresponds to a traditional consignment contract with a sharing agreement, where the two firms share the revenues according to a sharing rule, $\phi$. The consignment contract we describe is completely different with respect to the dynamic game literature on distribution channels that historically has analyzed a traditional wholesale price setting (e.g., De Giovanni, 2017). The main motivation for doing so is that no up-front motivation explains why retailers should accept contracts (e.g., a consignment contract) if they basically lose power over the channel. In fact, $R$ has one less variable to determine (e.g., price), thus losing decisional power.

Why should $R$ then accept this contract? The literature provides two operational reasons: First, she exploits the value of M's brand by boosting demand even without participating in it; second, she does not need to think about the price competition any more, but, rather, she needs to negotiate a sufficiently large $\phi$. From a strategic point of view, the literature has proposed several mechanisms to facilitate firms' coordination and make a consignment contract less painful for retailers. The first option is given by the chance that $M$ can provide support for $R$ 's advertising efforts to make the consignment contract more attractive: $R$ accommodates the contract that $M$ proposes and, although she loses some decisional power over the chain, she gets direct economic benefits as $M$ pays for a fraction of the store advertising efforts. We name this scenario the Cooperative Advertising Scenario (we denote it by the superscript $C$ ) and indicate the manufacturer's participation rate $P(t) \in(0,1)$. As a chain leader, $M$ decides a further control $P(t)$ after knowing $R$ 's advertising investments. The demand function $S^{C}$ takes the form of (2). Accordingly, the players' payoffs are modified as follows:

$$
\begin{aligned}
\max _{\substack{p^{C}(t), Q^{C}(t) \geq 0, 0<P^{C}(t)<1}} J_{M}^{C} & =\int_{0}^{+\infty} e^{-r t}\left\{S^{C}\left[p^{C}(t)(1-\phi)-c_{M}\right]-\frac{\mu_{M} Q^{C}(t)^{2}}{2}-\frac{\mu_{R} A^{C}(t)^{2} P^{C}(t)}{2}\right\} d t \\
\max _{A^{C}(t) \geq 0} J_{R}^{C} & =\int_{0}^{+\infty} e^{-r t}\left\{S^{C} p^{C}(t) \phi-\frac{\mu_{R} A^{C}(t)^{2}\left(1-P^{C}(t)\right)}{2}\right\} d t
\end{aligned}
$$

subject to (1) and to the initial condition $G(0)=G_{0}$. Compared to the benchmark scenario, $R$ will set her strategies

by knowing that $M$ will decide $P^{C}(t)$ optimally; thus, $P^{C}(t)>0$. Therefore, $R$ makes $M$ responsible for increasing the demand through the support program, although it does not directly affect its goodwill.

The second option available for supply chains is represented by granting $R$ the possibility of setting a discount, $\lambda(t)$. This practice is frequently used in the distribution channel when a retailer accepts that the manufacturer (brand's owner) 
sets the selling price while a discount applies to the fraction of revenues due to the retailer. In some instances, this practice allows retailers to protect their business against anticompetitive behaviors that manufacturers can undertake (Sacco and De Giovanni, 2019). In such a situation, $M$ still fixes the selling price, but $R$ can use a discount, which is her control variable. This type of mechanism allows $M$ to fully appropriate the marginal revenues, while $R$ can practice a discount relative to her own margins (we will denote this scenario by using the superscript $D$ ). Consequently, $\lambda(t)<p(t) \phi$, and $\pi_{R}=p(t) \phi-\lambda(t)$. This framework has an impact on both the demand function (2), which becomes

$$
S^{D}\left(p^{D}(t), A^{D}(t), G^{D}(t), \lambda(t)\right)=\alpha-\beta\left(p^{D}(t)-\lambda(t)\right)+\gamma G^{D}(t)+\theta A^{D}(t)
$$

and the state equation (1) which becomes

$$
\dot{G}(t)=a Q^{D}(t)+b\left(p^{D}(t)-\lambda(t)\right)-\delta G^{D}(t) .
$$

Observe that the positiveness of the state trajectories is guaranteed if $\lambda(t) \leq p^{D}(t)$. The discount $\lambda(t)$ has a dual effect: It increases sales and, at the same time, decreases $R$ 's marginal revenue. When taking this new strategy into consideration, the players' payoffs become:

$$
\begin{aligned}
\max _{p^{D}(t), Q^{D}(t) \geq 0} J_{M}^{D} & =\int_{0}^{+\infty} e^{-r t}\left\{S^{D}\left(p^{D}(t)(1-\phi)-c_{M}\right)-\frac{\mu_{M} Q^{D}(t)^{2}}{2}\right\} d t \\
\max _{\lambda^{D}(t), A^{D}(t) \geq 0} J_{R}^{D} & =\int_{0}^{+\infty} e^{-r t}\left\{S^{D}\left(p^{D}(t) \phi-\lambda(t)\right)-\frac{\mu_{R} A^{D}(t)^{2}}{2}\right\} d t
\end{aligned}
$$

subject to (8) and to the initial condition $G(0)=G_{0}$.

Unlike the other two scenarios, the discount allows $R$ to directly influence the goodwill stock. Because $M$ builds its goodwill also according to the price, the presence of a discount directly deteriorates that goodwill, although it leads to higher sales. Thus, this instrument can make $M$ 's proposal suitable because $R$ can control both the sales and the goodwill stock. Furthermore, it equilibrates the decisional power over the channel as both players have two strategies available for optimizing their profits. Although this mechanism is really appealing in principle, it basically destroys $M$ 's goodwill and enlarges the sales simultaneously; therefore, it contributes to firms' profits by increasing demand rather than goodwill accumulation.

We characterize a Stackelberg game where $M$ acts as leader and $R$ as follower. In sum, we consider three different scenarios. In the first scenario (benchmark, scenario $B), M$ sets the price, $p(t)$, and the quality strategies, $Q(t)$, while $R$ decides the store advertising efforts, $A(t)$. In the second scenario (cooperative advertising, scenario $C$ ), $M$ has a further control available that is represented by the participation rate, $P(t)$. Finally, in the third scenario (price discount, scenario $D), R$ applies a discount, $\lambda(t)$, to the retail price, while $M$ is not involved in the advertising efforts. As in Cachon and Lariviere (2005) and many other papers dealing with supply chain coordination, we assume that moving from one contract configuration to another and consequently updating the pricing strategies does not imply additional costs for firms or for 
consumers.

\section{$3 \quad$ Feedback Stackelberg equilibria and steady states}

We seek to derive and compare firms' strategies under the three scenarios earlier proposed. In this section, we present the analytical results and a characterization of the feedback Stackelberg equilibria and the steady states. In characterizing the feedback Stackelberg equilibria, we implicitly assume that firms employ stationary strategies where neither the strategies nor the value functions explicitly depend on time. Thus, for each scenario, we compute the optimal strategies, dropping the time argument from now on, when no ambiguity can arise. The Hamilton-Jacobi-Bellman (HJB) equations of all three scenarios turn out to be quadratic in $G$. Furthermore, the optimal trajectories will be either increasing and concave or decreasing and convex and they will approach the stable positive steady state, if it exists. In other words $G_{(t)}(t)\left(G_{0}, G_{S S}\right)$ if $G_{0}<G_{S S}$ and $G(t) \in\left(G_{S S}, G_{0}\right)$ if $G_{0}>G_{S S}$. As the signs of the coefficient of strategies and value functions cannot always be determined analytically, we will fully address the main insights from our models in the computation analysis section while developing a qualitative analysis.

Consider the following condition, which permits checking the second-order optimality conditions and the positivity of the equilibrium strategies in all three scenarios.

Condition 1 Let $\beta \mu_{R}-\theta^{2}>0$.

This condition can be rewritten as $\beta>\frac{\theta^{2}}{\mu_{R}}$. The ratio represents the advertising effectiveness as it explains the comparison between the marginal benefits that the channel gets in terms of sales and the negative effect that any marginal investment in advertising exerts on $R$ 's profits. Condition 1 explains that the importance of price is always larger than the importance of advertising, according to the idea that consumers always drive their decisions more according to price than according to advertising. This condition leads to a feasible solution as pricing and advertising strategies are positive only when this condition holds. Therefore, $M$ can use a consignment contract in his $\mathrm{SC}$ only when condition 1 is verified. Otherwise, he should do nothing, change the contract, or quit the SC.

\subsection{Benchmark $(B)$ Scenario}

Here we characterize the equilibria for the benchmark game, which consists of a consignment contract with a sharing agreement. In this game, $M$ announces that he will play the game by optimally choosing the price $p^{B}$ and the quality investments, $Q^{B} ; R$, who is the follower, reads this announcement and optimally determines the advertising efforts, $A^{B}$. Then, $M$ considers $R$ 's strategy and optimally sets his price and quality strategies. The next theorem characterizes the strategies and the value functions for this game. 
Theorem 1 The firms'strategies that constitute the Stackelberg equilibrium in the benchmark scenario are

$$
\begin{aligned}
A^{B}\left(G^{B}\right) & =\frac{\theta \phi p^{B}\left(G^{B}\right)}{\mu_{R}}=\frac{\theta \phi\left[b \mu_{R}\left(V_{M}^{B}\right)^{\prime}+\left(\alpha+\gamma G^{B}\right) \mu_{R}(1-\phi)+c_{M}\left(\beta \mu_{R}-\theta^{2} \phi\right)\right]}{\left[2(1-\phi)\left(\beta \mu_{R}-\theta^{2} \phi\right)\right] \mu_{R}}, \\
p^{B}\left(G^{B}\right) & =\frac{b \mu_{R}\left(V_{M}^{B}\right)^{\prime}+\left(\alpha+\gamma G^{B}\right) \mu_{R}(1-\phi)+c_{M}\left(\beta \mu_{R}-\theta^{2} \phi\right)}{2(1-\phi)\left(\beta \mu_{R}-\theta^{2} \phi\right)}, \\
Q^{B}\left(G^{B}\right) & =\frac{a\left(V_{M}^{B}\right)^{\prime}}{\mu_{M}} .
\end{aligned}
$$

The firms' value functions are given by:

$$
\begin{aligned}
& V_{M}^{B}\left(G^{B}\right)=M_{1}^{B}\left(G^{B}\right)^{2}+M_{2}^{B} G^{B}+M_{3}^{B}, \\
& V_{R}^{B}\left(G^{B}\right)=R_{1}^{B}\left(G^{B}\right)^{2}+R_{2}^{B} G^{B}+R_{3}^{B}
\end{aligned}
$$

$M_{i}^{B}$ and $R_{i}^{B}, i=1 . .3$, are constant parameters, $\left(V_{M}^{B}\right)^{\prime}$ is the derivative of $V_{M}^{B}$ w.r.t. $G^{B}$ and the goodwill at the stable steady state is

$$
G_{S S}^{B}=\frac{W_{1}(1-\phi) \alpha \mu_{R}-c_{M} W_{2}\left(\beta \mu_{R}-\theta^{2} \phi\right)-b^{2} c_{M} \gamma \mu_{M} \mu_{R}}{(1-\phi)\left(2 \delta \mu_{M}(\delta+r)\left(\beta \mu_{R}-\theta^{2} \phi\right)-\left(W_{1}+\delta b \mu_{M}\right) \gamma \mu_{R}\right)}
$$

with $W_{1}=\left(b \mu_{M}(r+\delta)+a^{2} \gamma(1-\phi)\right)$ and $W_{2}=\left(-b \mu_{M}(r+\delta)+a^{2} \gamma(1-\phi)\right)$.

Proof. See the online Appendix A.

Interestingly, one can see that all controls depend on $M$ 's value function but not also on $R$ 's value function. Thus, the larger M's economic convenience in increasing goodwill, the larger the controls. Regarding the demand function, we can see that a trade-off exists between pricing and advertising. In particular, the negative effect generated by pricing is fully compensated by the advertising efforts.

The analysis of both strategies and value functions depends on the signs of the coefficients $M_{i}^{B}, R_{i}^{B}$. When solving the Riccati system of equations, all coefficients are positive (see the computational analysis in the online Appendix A) so that the optimal manufacturer's quality investments $Q^{B}$ are positive and both the advertising efforts, $A^{B}$, and pricing, $p^{B}$, strategies are positive as well, thanks to Condition 1.

The goodwill stock allows both firms to increase their profits at the steady state. Therefore, both firms have an economic incentive to increase goodwill at the steady state as much as possible. $R$ achieves these results by advertising more to increase sales. This is a very interesting result with respect to the literature (e.g., Jørgensen and Zaccour, 2004). In fact, $R$ spends more in advertising even if her efforts do not influence the state. Furthermore, when goodwill at the steady state reaches a high value, the demand is positive independent of the advertising efforts. According to Jørgensen and Zaccour (2004), one would expect to have decreasing investments in advertising because of the relevant contribution of goodwill. Nevertheless, we obtain the opposite result. This happens because $R$ seeks to preserve her business independent of $M$ 's strategies. $R$ is in a weak position as the follower; thus, she sets the advertising strategies to achieve a certain level of sales regardless of $M$ 's moves. On the other hand, $M$ charges higher prices for two main reasons: First, the price is a signal of product quality and has a considerable influence in the goodwill stock; second, $M$ fixes a higher price without 
losing sales because he invests more in quality efforts to achieve higher values of goodwill. The latter decision is most likely linked to the trade-off entailed in the demand function between pricing and goodwill. Thus, increasing prices according to goodwill does not deteriorate sales.

\subsection{Cooperative advertising $(C)$ scenario}

In this section, we model a cooperative advertising game in which $M$ announces that he will pay a fraction of $R$ 's national advertising expenses. The cooperative program complements the consignment contract with the intent to coordinate the chain by making both firms economically better off compared to not having the program. This fraction, denoted by $P$, stays for the participation rate and is under $M$ 's control. Therefore, $M$ announces that he will play the game by optimally choosing the price, $p^{C}$, the quality investments, $Q^{C}$, and the participation rate, $P$. Then, $R$ acknowledges this announcement and optimally determines the advertising efforts, $A^{C}$. Finally, $M$ takes into consideration $R$ 's strategy and optimally sets his strategies. The next theorem characterizes the strategies and the value functions for this game.

Theorem 2 The firms' strategies that constitute the Stackelberg equilibrium in the cooperative advertising scenario are:

$$
\begin{aligned}
A^{C}\left(G^{C}\right) & =\frac{2 \theta\left[(2-\phi)\left((1-\phi)\left(\alpha+\gamma G^{C}\right)+b\left(V_{M}^{C}\right)^{\prime}\right)+\beta c_{M}(3 \phi-2)\right]}{8 \beta \mu_{R}(1-\phi)-\theta^{2}(2-\phi)^{2}}, \\
p^{C}\left(G^{C}\right) & =\frac{2\left[2 \mu_{R}\left((1-\phi)\left(\alpha+\gamma G^{C}\right)+b\left(V_{M}^{C}\right)^{\prime}\right)+c_{M}\left(2 \beta \mu_{R}-\theta^{2}(2-\phi)\right)\right]}{8 \beta \mu_{R}(1-\phi)-\theta^{2}(2-\phi)^{2}}, \\
Q^{C}\left(G^{C}\right) & =\frac{a\left(V_{M}^{C}\right)^{\prime}}{\mu_{M}}, \\
P\left(G^{C}\right) & =\frac{\mu_{R}(2-3 \phi)\left[(1-\phi)\left(\alpha+\gamma G^{C}\right)+b\left(V_{M}^{C}\right)^{\prime}\right]-c_{M}(2-\phi)\left(\beta \mu_{R}-\theta^{2} \phi\right)}{\mu_{R}(2-\phi)\left[(1-\phi)\left(\alpha+\gamma G^{C}\right)+b\left(V_{M}^{C}\right)^{\prime}\right]+\beta c_{M} \mu_{R}(3 \phi-2)}
\end{aligned}
$$

and the firms' value functions are given by:

$$
\begin{aligned}
& V_{M}^{C}\left(G^{C}\right)=M_{1}^{C}\left(G^{C}\right)^{2}+M_{2}^{C} G^{C}+M_{3}^{C}, \\
& V_{R}^{C}\left(G^{C}\right)=R_{1}^{C}\left(G^{C}\right)^{2}+R_{2}^{C} G^{C}+R_{3}^{C},
\end{aligned}
$$

where $M_{i}^{C}$ and $R_{i}^{C}, \quad i=1 . .3$, are constant parameters and $\left(V_{M}^{C}\right)^{\prime}$ is the derivative of $V_{M}^{C}$ w.r.t. $G^{C}$. The goodwill at the stable steady state is

$$
G_{S S}^{C}=\frac{a^{2} \gamma W_{3}+4 b^{2} \gamma c_{M} \mu_{M} \mu_{R}-2 b \mu_{M}(\delta+r)\left(2 \alpha \mu_{R}(1-\phi)+c_{M}\left(2 \beta \mu_{R}-\theta^{2}(2-\phi)\right)\right)}{4 a^{2} \gamma^{2} \mu_{R}(1-\phi)^{2}+4 b \gamma \mu_{M} \mu_{R}(1-\phi)(2 \delta+r)-\delta \mu_{M}(\delta+r)\left(8 \beta \mu_{R}(1-\phi)-\theta^{2}(2-\phi)^{2}\right)},
$$

where $W_{3}=\left(c_{M}\left(4 \beta \mu_{R}(1-\phi)-\theta^{2}(2-\phi) \phi\right)-4 \alpha \mu_{R}(1-\phi)^{2}\right)$.

Proof. See the online Appendix A.

The analysis of both strategies and value functions depends on the signs of the coefficients $M_{i}^{C}, R_{i}^{C}$ whose associated Riccati system of equations is given in the online Appendix A together with the associated positive coefficients. Therefore, the derivatives $\left(V_{M}^{D}\right)^{\prime}$ and $\left(V_{R}^{D}\right)^{\prime}$ of the value functions are also positive. This implies that the manufacturer's quality 
effort $Q^{C}$ and the numerator of (18) are positive. To guarantee a positive pricing strategy $p^{C}$, we must ensure that the denominator is also positive. Thus, we need to establish the following condition:

Condition 2 Let $8 \beta \mu_{R}(1-\phi)-\theta^{2}(2-\phi)^{2}>0$.

Condition 2 is more restrictive than Condition 1 as it also considers the sharing parameter $\phi$. The two conditions are driven by the same economic motivations and together ensure optimality of the second-order conditions and the positivity of the strategies. One can see that $P<1$ and that all strategies increase in $G$. Condition 2 leads to a positive denominator for $p^{C}$ and $A^{C}$ and also makes positive the numerator of $p^{C}$. One can verify that if the numerator of $A^{C}$ is positive, then $P$ is also positive. When Condition 2 does not hold, the solution is not feasible as pricing and advertising strategies are negative. Consequently, $M$ never complements a consignment contract with a cooperative program.

The findings in the cooperative scenario basically follow those in the benchmark scenario; that is, both firms are highly interested in higher stocks of goodwill as their profits always increase accordingly. In addition, the participation rate increases in the goodwill stock. A high value for the goodwill reflects an effective policy and the importance of the overall business. To protect the related economic value, $M$ can also support a fraction of $R$ 's advertising efforts, thus having some control in $R$ 's strategy and, consequently, more power over the channel. Intuitively, when consumers are marginally sensitive to goodwill (low $\gamma$ ), $M$ would pay a fraction of $R$ 's advertising efforts; in such a case, struggling to increase the stock of goodwill does not pay off.

Because strategies, states, and profit functions depend heavily on all the model's parameters, a deep comparison with the benchmark scenario is possible only numerically. We develop a full computational analysis in Section 4 and in the online Appendix B.

\subsection{Price discount $(D)$ scenario}

In this section, we model a price discount scenario, in which $M$ announces that he will allow $R$ to discount the retail price. The discount is denoted by $\lambda$ and consists of the lower amount of money that consumers pay when purchasing the product. The discount is set by $R$, who now has two controls available, price discount, $\lambda$, and advertising efforts, $A^{D}$. In the $D$-scenario, $M$ announces that he will play the game by optimally choosing the price $p^{D}$, along with the quality investments, $Q^{D}$, while accommodating a price discount; $R$ acknowledges this announcement and optimally determines

the advertising efforts, $A^{D}$, and the price discount $\lambda$. Then, $M$ considers $R$ 's strategies and optimally sets the price and the quality efforts. The next theorem characterizes the strategies and the value functions for this game. 
Theorem 3 The firms' strategies that constitute the Stackelberg equilibrium in the cooperative advertising scenario are:

$$
\begin{aligned}
A^{D}\left(G^{D}\right)= & \frac{\theta\left[\beta \mu_{R}\left(3 b\left(V_{R}^{D}\right)^{\prime}-b\left(V_{M}^{D}\right)^{\prime}+\alpha-\beta c_{M}+\gamma G\right)+b \theta^{2}\left(\left(V_{M}^{D}\right)^{\prime}-\left(V_{R}^{D}\right)^{\prime}\right)\right]}{2 \beta \mu_{R}\left(2 \beta \mu_{R}-\theta^{2}\right)}, \\
p^{D}\left(G^{D}\right)= & \frac{b\left(\beta \mu_{R}-\theta^{2}\right)\left(\left(V_{M}^{D}\right)^{\prime}-\left(V_{R}^{D}\right)^{\prime}\right)+\beta \mu_{R}\left(\alpha+\beta c_{M}+\gamma G^{D}\right)}{2 \beta^{2} \mu_{R}(1-\phi)}, \\
Q^{D}\left(G^{D}\right)= & \frac{a\left(V_{M}^{D}\right)^{\prime}}{\mu_{M}}, \\
\lambda\left(G^{D}\right)= & \frac{-2 \beta^{2} \mu_{R}^{2}(1-\phi)\left(b\left(V_{R}^{D}\right)^{\prime}+\alpha+\gamma G^{D}\right)}{\left(2 \beta \mu_{R}-\theta^{2}\right)\left(2 \beta^{2} \mu_{R}(1-\phi)\right)} \\
& +\frac{\left(\phi\left(\beta \mu_{R}-\theta^{2}\right)+\beta \mu_{R}\right)\left(b\left(\beta \mu_{R}-\theta^{2}\right)\left(\left(V_{M}^{D}\right)^{\prime}-\left(V_{R}^{D}\right)^{\prime}\right)+\beta \mu_{R}\left(\alpha+\beta c_{M}+\gamma G^{D}\right)\right)}{\left(2 \beta \mu_{R}-\theta^{2}\right)\left(2 \beta^{2} \mu_{R}(1-\phi)\right)}
\end{aligned}
$$

and the firms' value functions are given by:

$$
\begin{aligned}
& V_{M}^{D}\left(G^{D}\right)=M_{1}^{D}\left(G^{D}\right)^{2}+M_{2}^{D} G^{D}+M_{3}^{D}, \\
& V_{R}^{D}\left(G^{D}\right)=R_{1}^{D}\left(G^{D}\right)^{2}+R_{2}^{D} G^{D}+R_{3}^{D},
\end{aligned}
$$

where $M_{i}^{D}$ and $R_{i}^{D}, \quad i=1 \ldots 3$, are constant parameters, $\left(V_{M}^{D}\right)^{\prime}$ and $\left(V_{R}^{D}\right)^{\prime}$ are the derivatives of $\left(V_{M}^{D}\right)$ and $V_{R}^{D}$, respectively, w.r.t. $G^{D}$. The goodwill at the stable steady state is

$$
G_{S S}^{D}=-\frac{b \mu_{M}\left(\beta \mu_{R}\left(\alpha+\beta c_{M}\right)+b\left(M_{2}^{D}-R_{2}^{D}\right)\left(\beta \mu_{R}-\theta^{2}\right)\right)+2 a^{2} \beta^{2}(1-\phi) M_{1}^{D} \mu_{R}}{\mu_{M}\left(2 b^{2}\left(M_{1}^{D}-R_{1}^{D}\right)\left(\beta \mu_{R}-\theta^{2}\right)+\beta \mu_{R}(b \gamma-2 \beta \delta(1-\phi))\right)+4 a^{2} \beta^{2}(1-\phi) M_{1}^{D} \mu_{R}} .
$$

Proof. See the Appendix.

As for the other scenarios, the analysis of both strategies and value functions depends on the signs of the coefficients $M_{i}^{D}, R_{i}^{D}$. Solving the Riccati system of equations, one can verify that all coefficients are positive (see the computational analysis in the online Appendix B). Thus, as in the $B$-scenario, condition 1 is sufficient to guarantee positive necessary conditions.

In addition to the insights from the other two scenarios, we can prove that the optimal discount $\lambda$ is smaller than the price $p^{D}\left(\lambda<p^{D}\right)$ and this ensures positive state trajectories (see the online Appendix A). Also, the discount $\lambda$ depends on the stock of goodwill: One can numerically check that when goodwill takes high values, the channel exploits the positive effects on sales and profits; thus, $R$ sets lower $\lambda$ to avoid diminishing the stock of goodwill. The optimal price $p^{D}$ in Eq. (24) increases in $G^{D}$ and so does the manufacturer's optimal quality effort $Q^{D}$. Therefore, $M$ protects his brand value by increasing the selling price when $R$ can practice a discount. The presence of a discount does not hurt $M$ 's profits, as he adjusts his strategies accordingly. We evaluate the overall convenience of adopting a price discount mechanism numerically in Section 4 and in the online Appendix B. 


\section{Computational analysis}

The Riccati system of equations linked to each of the proposed scenarios shows recursive relationships between the pair of quadratic coefficients $M_{1}^{j}, R_{1}^{j}$, with $j=B, C, D$ (see the online Appendix B). Therefore, we must perform a computational analysis to compare the solutions. In fact, all strategies, states, sales, and profit functions consist of heavy network relationships among all the model's parameters that prevent an analytical analysis. We confine our investigation to the long-term behavior, hence focusing on the steady state analysis. In fact, we seek to identify the conditions under which supply chain members are economically better off through coordination via either a cooperative program or a discount policy. Nevertheless, we display a full dynamic analysis in the online Appendix C for readers who are interested in the evolution of strategies, states, sales, and profits. Note that the findings at the steady state hold for any $t$. Interestingly, the firms' decisions and the outcomes are largely influenced by the amplitude of all parameter values. We display a full computational analysis in the online Appendix B by setting the following parameters as baseline values:

Demand parameters: $\alpha=10, \beta=1, \gamma=0.2, \theta=1$.

Operational parameters: $c_{M}=5, \mu_{M}=\mu_{R}=2.5$.

Goodwill parameters: $a=b=0.5, \delta=0.4$.

Discount parameters: $r=0.1$.

Contract parameters: $\phi=0.28$.

These parameters, which we select based on previous studies in marketing and operations management in feedback form (e.g., De Giovanni, 2016a, b), allow for a comprehensive comparison of the games. Note that the solutions obtained when solving the Riccati systems are not unique. In fact, two of the polynomial equations within each scenario are quadratic. In scenarios $B$ and $C$, the Riccati system has two solutions, and in scenario $D$, it has four. We then select the optimal solution according to which strategies, goodwill, and profits are always positive, $P \in(0,1)$, the second-order conditions are always satisfied, and the steady states are stable. To provide a robust and comprehensive investigation of our findings, we conduct a parametric sensitivity analysis, as reported in the online Appendix B. This analysis allows us to compare the strategies and the payoffs and to show their variations at the steady state when a certain parameter varies. By using the earlier fixed parameter values, we obtain an initial solution that is displayed in Table 1. 


\begin{tabular}{|c|c|c|c|}
\hline & Benchmark & Cooperative advertising & Price discount \\
\hline$V_{R}$ & 7.190 & 7.652 & 4.739 \\
\hline$V_{M}$ & 8.857 & 9.448 & 9.443 \\
\hline$G$ & 14.294 & 14.859 & 14.912 \\
\hline$A$ & 1.253 & 1.997 & 1.048 \\
\hline$p$ & 11.191 & 11.618 & 12.608 \\
\hline$Q$ & 0.245 & 0.269 & 0.231 \\
\hline$P$ & - & 0.348 & - \\
\hline$\lambda$ & - & - & 0.909 \\
\hline$V_{S C}$ & 16.048 & 17.100 & 14.182 \\
\hline$S$ & 2.922 & 3.350 & 2.332 \\
\hline$M_{1}$ & 0.010378 & 0.01182 & 0.008312 \\
\hline$M_{2}$ & 0.926235 & 0.99465 & 0.905995 \\
\hline$M_{3}$ & 73.2105 & 77.0893 & 79.0688 \\
\hline$R_{1}$ & 0.003752 & 0.00438 & 0.004161 \\
\hline$R_{2}$ & 0.686105 & 0.73924 & 0.454069 \\
\hline$R_{3}$ & 61.3306 & 64.5652 & 39.6916 \\
\hline
\end{tabular}

When selecting the baseline parameter values, we aim at starting from the situation in which $M$ is indifferent between the implementation of cooperative advertising and a price discount program, e.g., $V_{M}^{C} \simeq V_{M}^{D}$. Then, in the online Appendix B, we develop a simulation analysis on all parameters to see how the leader's preferences change accordingly. Note that the baseline parameter values is not a unique set of parameters for having $V_{M}^{C} \simeq V_{M}^{D}$. In fact, several sets still allow the findings of this paper to hold. Independent of the set of parameters that leads to a feasible solution, a clear result emerges: $M$ prefers the implementation of a coordination mechanism, as $V_{M}^{B}<V_{M}^{C}=V_{M}^{D}$. Thus, we start our analysis from $R$ 's preferences, strategies, and states when $M$ is indifferent between coordination mechanisms (Section 4.1). Then, we analyze whether $M$ 's preferences change when some of the model's parameters vary, thus $V_{M}^{C} \neq V_{M}^{D}$ (Section 4.2); finally, we identify the conditions according to which SC members can reach a profit-Pareto-improving situation through coordination (Section 4.3).

\subsection{Games comparison when the leader is indifferent between coordination mechanisms}

The sensitivity analysis displayed in the online Appendix B reveals the conditions under which $R$ 's preferences concerning the implementation of a coordination mechanism change while $M$ is indifferent between a cooperative advertising program and a price discount mechanism. All findings are displayed in the following claim.

Claim 1 When $M$ is indifferent between a cooperative advertising and a price discount programs, $R$ is better off through the implementation of cooperative advertising (e.g., $\left.V_{R}^{C}>V_{R}^{D}\right)$. 
This finding links to several motivations. First, with a price discount mechanism, $R$ is responsible for coordination of the supply chain. When $\lambda=0$, the firms' strategies and profits along with the state yield back the benchmark solution. The discount has a direct deteriorating effect on $R$ 's margins, which implies a considerable decrease in her revenues. In contrast, a price discount program guarantees a certain level of profits to $M$ because his margins $($ i.e., $p(1-\phi))$ are not influenced by the discount. Rather, he will benefit from larger sales. Although $R$ benefits from an additional control to optimize her objective function, her margins reduce drastically. Second, because $R$ receives lower profits, she has less willingness to invest in advertising. Thus, the entire supply chain suffers from these circumstances. In contrast, a cooperative advertising program allows $R$ to preserve her margins and be better off even if $M$ controls the price. The presence of a cooperative program substantially reduces her advertising expenses. Overall, anytime $M$ gives $R$ the possibility to discount, she will dislike coordination and prefer a consignment contract as in Scenario $B$. Note that the finding displayed in Claim 1 holds every time $V_{M}^{C}=V_{M}^{D}$. More in general, given a set of possible combinations of parameter values $\Sigma$, there exists a set $N \subset \Sigma$, which is composed of $n$ elements, such that $V_{M}^{C}=V_{M}^{D}$ and $V_{R}^{C}>V_{R}^{D}, \forall n \in N \subset \Sigma$.

Claim 2 When $M$ is indifferent between cooperative advertising and price discount program, the following results hold:

1. $M$ sets higher prices under a price discount program (i.e., $p^{D}>p^{C}$ ).

2. $R$ makes larger advertising efforts with cooperative advertising (i.e., $A^{C}>A^{D}$ ).

3. $M$ makes greater quality improvement efforts with cooperative advertising (i.e., $Q^{C}>Q^{D}$ ).

4. The implementation of a cooperative program always maximizes the social welfare (i.e., $\left.S^{C}>S^{D}\right)$.

5. The SC extracts more economic value from the market with cooperative advertising $\left(i . e ., V_{S C}^{C}>V_{S C}^{D}\right)$.

Under a price discount program, $R$ can substantially damage $M$ 's brand value (goodwill) when discounting aggressively. To protect his brand, $M$ fixes a higher price and avoids losing the price contribution in the accumulation of goodwill. Interestingly, the price under a cooperative program $p^{C}$ and the discounted price $p^{D}-\lambda$ are very much comparable. Even so, consumers will purchase more under a cooperative advertising program (Point 4), which is more effective to increase the social welfare. The latter consists of the number of people who purchase the good to satisfy their needs; therefore, higher sales reflect higher social outcomes (De Giovanni, 2018). This is due not only to the lower price under cooperative advertising programs that stimulates demand, but also to the larger advertising and quality efforts that firms invest (Points 2 and 3). This result is aligned with the literature on cooperative advertising, which highlights that the presence of a support program pushes up the advertising investments of the entire supply chain (e.g., Jørgensen and Zaccour, 2004). This is also expected in other contexts such as quality management (De Giovanni, 2011), innovation (Geyer, 2015), and promotion (Karray, 2016). More generally, cooperative programs such as those implemented in the $C-$ scenario incentivize all firms to make a stronger commitment. As a consequence, the demand increases directly through the larger $R$ 's advertising efforts as well as indirectly through the larger goodwill stocks generated by the greater $M$ 's quality efforts. With our models, we have checked that this positive willingness induced by a coordination mechanism exists not only in traditional settings in which retailers set the price (e.g., wholesale price and revenue-sharing contracts) but also in contexts where manufacturers decide the retail price (e.g., consignment contracts). Because a cooperative program stimulates the demand more than the other contracts, it allows firms to also maximize their social performance, as exemplified by a 
larger amount of consumers who can afford the good and be satisfied. Overall, the adoption of a cooperative program entails a supply chain extracting more economic value from the market (Point 5). This result derives from the effect that pricing, quality, and advertising strategies have on the demand as well as on the goodwill. $R$ 's profit is the key element for analyzing the value creation within this supply chain. Under a price discount program, $R$ offers a discount that directly and solely affects her profit margins while preserving $M$ 's marginal revenues. Thus, a price discount mechanism destroys some economic value since $R$ substantially cuts the store advertising expenses (in Table 1 , she cuts the advertising efforts by $90 \%$ compared to the cooperative program) while $M$ charges higher prices to favor the price discount (in Table $1, p^{D}$ is $7 \%$ greater than $p^{C}$ ). Overall, less advertising and a higher price substantially affect the economic value creation.

\subsection{Leader's choices and preferences}

The online Appendix B displays the sensitivity analysis of all parameter values. Starting from the aforementioned benchmarks, we take low and high values for each parameter by considering $\pm 20 \%$ variations (e.g., $\alpha=10$ with a low value of 8 and high value of 12). Accordingly, we can identify how a single parameter variation influences $M$ 's coordination preferences. Recall that the benchmark parameter values result in $V_{M}^{C} \simeq V_{M}^{D}$; thus, any marginal variation in a parameter modifies this relationship. In particular, $M$ will always prefer the implementation of a cooperative advertising program inside the space of parameter values $\Omega$, as detailed in the following claim.

Claim 3 M opts for the implementation of a cooperative advertising program inside the space $\Omega$, which is composed of all elements $\alpha>\widetilde{\alpha}, \beta<\widetilde{\beta}, \gamma>\widetilde{\gamma}, \delta<\widetilde{\delta}, \phi<\widetilde{\phi}, \mu_{M}<\widetilde{\mu_{M}}, \mu_{R}<\widetilde{\mu_{R}}, r<\widetilde{r}, a>\widetilde{a}, b>\widetilde{b}, c_{M}<\widetilde{c_{M}}, \theta>\widetilde{\theta}^{1}$.

When the market expands (high $\alpha$ ), $M$ knows that $R$ advertises more. Thus, $M$ announces the adoption of a cooperative program to increase sales even more through enhanced advertising and support. Conversely, $M$ prefers a price discount program with scarce market opportunities (low $\alpha$ ), thus preferring a more aggressive price discount strategy. $M$ is always economically better off through a cooperative advertising program with low consumer sensitivity to price (low $\beta$ ). A contract scheme that works on the price discount is ineffective when consumers are marginally affected by a price change. In contrast, high consumer sensitivity to $M$ 's goodwill and $R$ 's advertising (high $\theta$ and $\gamma$, respectively) make a cooperative program always preferable. In fact, $M$ knows that advertising and quality strategies are important for consumers and, consequently, both expenses increase substantially. Also, $R$ advertises even more than under a price discount mechanism since the support program is in place. Firms avoid the implementation of cooperative advertising under a quick goodwill decay rate. The supply chain then concentrates on sales, while the goodwill simply becomes less important. Thus, the chain leader adopts a price discount because it can positively affect sales through a lower price without compromising directly his marginal profits. This situation also occurs for high advertising efficiency (low $\mu_{R}$ ) and quality efficiency (low $\left.\mu_{M}\right)$. In these cases, in fact, supporting $R$ 's advertising expenses can be costly due to the evident negative impact on $M$ 's profits. The leader announces the adoption of a cooperative program only when advertising is both effective (high $\theta$ ) and

\footnotetext{
${ }^{1}$ The mark $\sim$ identifies a threshold value for a given parameter. For example, the proposition holds for $\forall \alpha>\widetilde{\alpha}$, where $\widetilde{\alpha}$ is a threshold for parameter $\alpha$.
} 
efficient $\left(\right.$ low $\mu_{R}$ ). Intuitively, a greater $\phi$ implies a larger amount of revenues granted to $R$ and, consequently, a larger chance to offer an important consumer deal through the price discount. Thus, the leader will announce the adoption of a cooperative program only when he retains the largest part of the revenues. Offering a support program to $R$ is a successful lever to collaborate and over-perform from an economic perspective. When $M$ 's control of his goodwill is largely effective, he will prefer a cooperative advertising coordination mechanism. This situation can be explained by large $a$ and $b$ values. So, the entire supply chain enjoys the benefits generated by the goodwill stock. At the same time, $M$ will most likely avoid a price discount mechanism because the goodwill can be seriously damaged by $R$ 's discount policy. This finding shows the importance of the dynamic components. When the dynamic components are highly relevant for $M$ 's profits, he prefers a cooperative program. The latter allows $M$ to better control $R$ 's advertising and its effect on demand. In contrast, a price

discount mechanism gives more control over the goodwill to $R$, which is an unfortunate situation that $M$ would surely avoid. Finally, a low marginal production cost, $c_{M}$, is an ideal case for $M$ to propose a cooperative advertising program. In fact, $M$ needs a minimal fraction of marginal revenues $p(1-\phi)$ to fully recover his production cost.

\subsection{Profit-Pareto-improving conditions and coordination}

We seek now to identify the conditions under which coordination can be reached, which means identifying a profit-Paretoimproving region. It will then be sufficient to use the results displayed in the previous claims.

Claim 4 A profit-Pareto-improving region exists when SCs adopt a cooperative program inside the space $\Omega$.

According to the computation analysis reported in the online Appendix $\mathrm{B}$ and the earlier mentioned claims, $R$ will always be better off with the implementation of a cooperative program. Furthermore, from Claim 3, $M$ will always be better off with the adoption of a cooperative program conditioned to living in space $\Omega$. Therefore, any time the SC lives in an environment in which the nature can be exemplified by the space region $\Omega, M$ announces the implementation of a cooperative advertising program and $R$ appreciates this announcement. Both firms achieve larger profits when adopting a cooperative program in $\Omega$, thus resulting in a profit-Pareto-improving situation. 

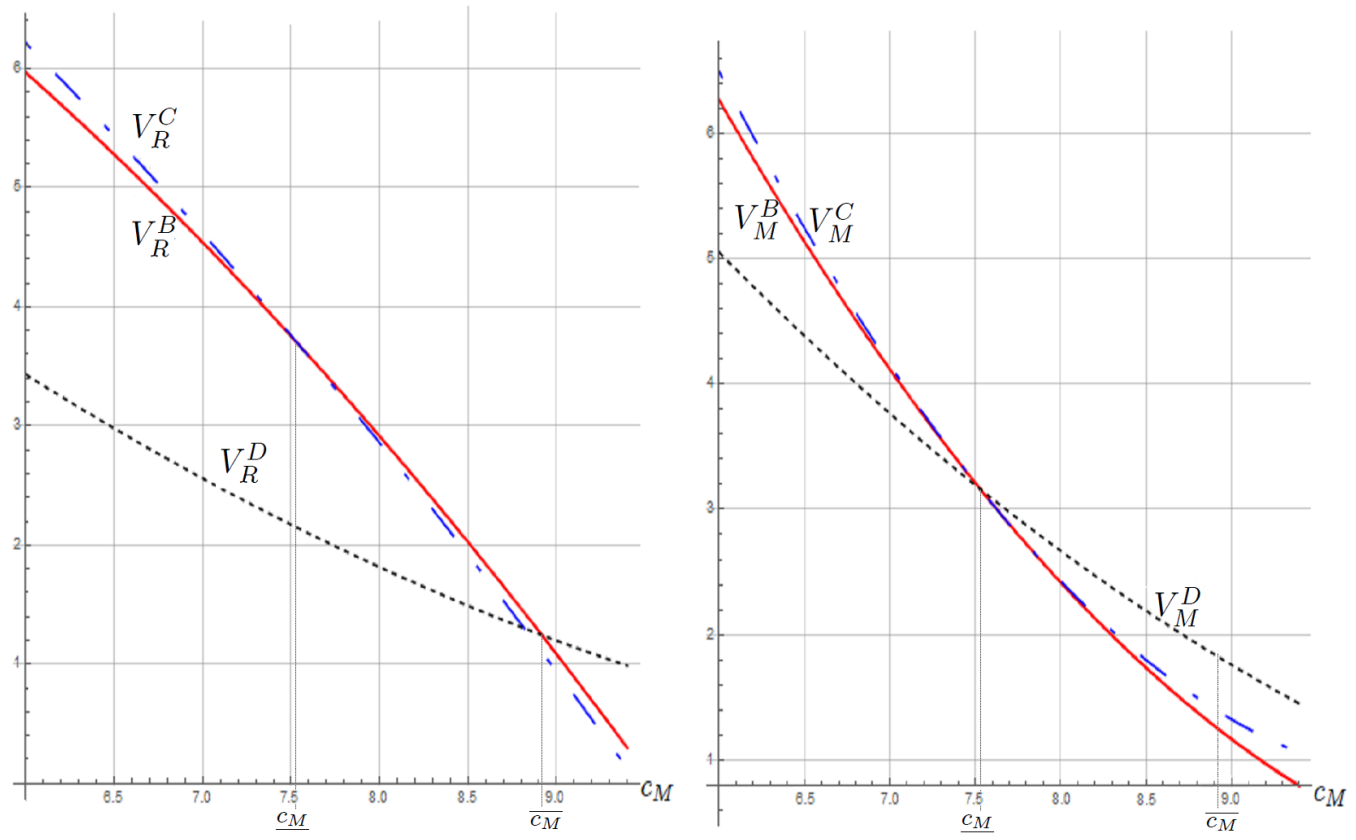

Figure 1. M's and R's profits with the marginal production cost, $c_{M}$.

The analysis of the marginal production cost deserves special attention. As we have mentioned, high marginal production costs lead $M$ to prefer a price discount mechanism, essentially because high prices can prevent consumers from purchasing a good. In fact, price is still one of the most important variables driving consumer decisions. Therefore, the positive impact that the price has on the goodwill stock is not corroborated by higher profits due to an important sales decrease. In such situations, a price discount mechanism can be of great help. The discount applies to the price directly, thereby alleviating the consumers' pain during the purchasing phase. Contrary to all other parameters, we note that very high marginal production costs, $c_{M}$, lead firms to change their preferences. In particular, $M$ prefers a price discount for $c_{M}>\underline{c_{M}}$ while $R$ is willing to implement a price-discount mechanism when $c_{M}>\overline{c_{M}}$. This result highlights an interesting intuition: When firms work in SCs with a cost-intense production process, the adoption of a price discount mechanism is the most preferred option (e.g., automotive sector); when firms work in low cost-intense SCs (e.g., electronics and fashion sectors), a cooperative advertising program remains the best option. Finally, in accordance with Figure 1, we can identify three levels of $c_{M}$ to set the firms' preferences:

1. $c_{M} \leq \underline{c_{M}}$ : Both firms prefer a cooperative advertising program, which leads to a profit-Pareto-improving situation.

2. $\underline{c_{M}}<c_{M}<\overline{c_{M}}$ : Firms have divergent preferences so a profit-Pareto-improving situation is never reached. $M$ opts for a price discount program, which will lead to more advertising and sales; in contrast, $R$ prefers a classical consignment contract because the high selling price makes the entire business less interesting for her.

3. $c_{M} \geq \overline{c_{M}}$ : Both firms support the adoption of a price discount program, which turns out to be profit-Paretoimproving. 


\section{Conclusions}

In this paper, we investigate whether a supply chain that uses a consignment contract with a revenue-sharing rule leads to an increase in profits through the implementation of either a cooperative advertising program or a price discount mechanism. When this happens, the SC better mimics the vertical integration solution and achieves coordination. In our model, the pricing strategy plays a key role along with quality improvements in contributing to the manufacturer's goodwill. The latter is built up over time according to the pricing and quality improvement strategies. We then use a consignment contract with a revenue-sharing agreement, which represents the basic case in which the manufacturer sets the retail price, products are sold by retailers who have no say on the price and firms split the overall revenues. Retailers invest in advertising to attract more consumers and increase sales by letting consumers know about the presence of certain products in their stores. Thus, we evaluate the suitability of complementing a consignment contract with a cooperative advertising program or a price discount mechanism to improve the firms' profits. In a cooperative advertising program, the manufacturer supports a part of the retailer's store advertising efforts while the retailer can practice some price reduction under a price discount mechanism.

Our findings suggest that retailers, being in the weaker position, carry out an intense negotiation process before entering into any type of business with manufacturers in an attempt to improve the results obtained through a consignment contract. In fact, the proper negotiation of the sharing parameter allows retailers to gain as much as the manufacturers independent of the setting. From our model, we learn that firms' profits are somehow comparable; thus, retailers can effectively negotiate on some contract terms (e.g., the sharing rule) to be economically satisfied. Our results suggest that the manufacturer is the firm most interested in moving away from a simple consignment contract. The adoption of cooperative advertising programs as well as price discount mechanisms is always largely profitable for manufacturers: Since they are leaders, retailers should expect that one of these two mechanisms will be pushed out.

Moving from a consignment contract to a consignment contract with a cooperative advertising program is always economically worthwhile for a manufacturer. This is an interesting result in the evaluation of cooperative advertising programs. Most of the literature on supply chains and distribution channels reveals that the firm that offers such types of collaborative programs needs to check the conditions under which profits are improved (e.g., De Giovanni (2001), Karray (2006), Martin-Herran and Sigue (2016), Jørgensen and Zaccour (2014)). In fact, this contract is always economically worthwhile for the receiver while being sometimes detrimental for the donor's profits, for example, when the participation rate is too high. Instead, our results suggest that this mechanism coordinates the supply chain; for example, both firms are economically better off (profit-Pareto-improving). Indeed, this result applies when the manufacturer constructs its goodwill according to quality improvement efforts and a proper pricing strategy, while retailers only think about their advertising efforts to enhance business, without any interference on either the pricing strategy or the accumulation of goodwill.

When the retailer applies a discount, it hurts the manufacturer's goodwill and, above all, directly damages its own profit margins. Consequently, the shift from a consignment contract to a consignment contract with a price discount makes retailers economically worse off. Thus, if firms agree to adopt a price discount mechanism during the negotiation 
process, retailers will most likely sign the contract and then set a null discount, thus ending up with a traditional consignment contract. This can be dangerous for manufacturers because complementing a consignment contract with a price discount mechanism is always economically convenient for them but convincing retailers to set a positive discount is highly challenging. We suggest that manufacturers check the impact of the marginal production cost on the entire business because this is the only feature that allows retailers to also be better off by using a price discount mechanism: When the production cost is very high, a discount can be beneficial for the entire supply chain (profit-Pareto-improving) while cooperative advertising turns out not to apply.

To sum up, if manufacturers seek to improve their profits under a simple consignment contract, a cooperative advertising program should be offered to retailers, who will always be willing to accept. Indeed, manufacturers should offer a cooperative advertising program when it is convenient compared to other options. When the price discount appeals to manufacturers more than a cooperative program, their decision will be made according to the marginal production cost: When it is high, manufacturers should propose a price discount program; when it is low, they should propose a cooperative advertising program because the retailers will most likely avoid price discounts.

This research has some limitations, which are highlighted here to inspire further research in this domain. One can easily extend the model proposed in this research to the case of multiple, competitive retailers. Also, we assume that the retailer's share is exogenous, while it can be endogenized according to its commitments (e.g., advertising efforts). Other strategies can also be accommodated in this model, including innovation, post-sale service, and logistics. Other conventional mechanisms can complement these contracts, such as a quantity discount, sales rebate, and vendor-management inventory. These types of contracts should be compared to conventional contracts in which the retailer decides the price to better understand who should decide the price within supply chains to benefit all supply chain members. This is an ongoing research direction that the authors have undertaken.

\section{References}

[1] Adida, E., \& Ratisoontorn, N. (2011). Consignment contracts with retail competition. European Journal of Operational Research, 215(1), 136-148.

[2] Aust, G., \& Buscher, U. (2014). Cooperative advertising models in supply chain management: A review. European Journal of Operational Research, 234(1), 1-14.

[3] Avinadav T., Chernonog T., Perlman Y. (2015) Consignment contract for mobile apps between a single retailer and competitive developers with different risk attitudes. European Journal of Operational Research, 246, 949-957.

[4] Avinadav T., Chernonog T., Perlman Y. (2015) The effect of risk sensitivity on a supply chain of mobile applications under a consignment contract with revenue-sharing and quality investment. International Journal of Production Economics, 168, 31-40.

[5] Avinadav T., Chernonog T., Perlman Y. (2017) Mergers and acquisitions between risk-averse parties. European Journal of Operational Research, 259, 926-934. 
[6] Battini, D., Grassi, A., Persona, A., \& Sgarbossa, F. (2010). Consignment stock inventory policy: Methodological framework and model. International Journal of Production Research, 48(7), 2055-2079.

[7] Ben-Daya, M., Hassini, E., Hariga, M., \& AlDurgam, M. M. (2013). Consignment and vendor managed inventory in single-vendor multiple buyers supply chains. International Journal of Production Research, 51(5), 1347-1365.

[8] Bernstein, F., Chen, F., \& Federgruen, A. (2006). Coordinating supply chains with simple pricing schemes: The role of vendor-managed inventories. Management Science, 52(10), 1483-1492.

[9] Borrell Associates Report (2015). Available at http://www2.netsertive.com/1/30602/2015-08-11/3z8jbc. Accessed on Oct 272016 .

[10] Buratto, A., \& Zaccour, G. (2009). Coordination of advertising strategies in a fashion licensing contract. Journal of optimization theory and applications, 142(1), 31-53.

[11] Buratto, A. (2013). Advertising and price to sustain the brand value in a licensing contract. In Advances in Dynamic Games (pp. 377-394). Birkhäuser Boston.

[12] Buratto, A., Grosset, L., \& Viscolani, B. (2016). Endogenous royalty factor in a licensing contract. Yugoslav Journal of Operations Research, 26(3).

[13] Cachon, G. P. (2004). The allocation of inventory risk in a supply chain: Push, pull, and advance-purchase discount contracts. Management Science, 50(2), 222-238.

[14] Cachon, G. P., \& Lariviere, M. A. (2005). Supply chain coordination with revenue-sharing contracts: Strengths and limitations. Management Science, 51(1), 30-44.

[15] Chen, L. T. (2013). Dynamic supply chain coordination under consignment and vendor-managed inventory in retailercentric B2B electronic markets. Industrial Marketing Management, 42(4), 518-531.

[16] Cho, R. K., \& Gerchak, Y. (2005). Supply chain coordination with downstream operating costs: Coordination and investment to improve downstream operating efficiency. European Journal of Operational Research, 162(3), 762-772.

[17] Chernonog T., Avinadav T. (2017) Pricing and advertising in a supply chain of perishable products under asymmetric information. International Journal of Production Economics, https://doi.org/10.1016/j.ijpe.2017.10.002

[18] De Giovanni, P. (2011). Quality improvement vs. advertising support: Which strategy works better for a manufacturer? European Journal of Operational Research, 208(2), 119-130.

[19] De Giovanni, P. (2018). A joint maximization incentive in closed-loop supply chains with competing retailers: The case of spent-battery recycling. European Journal of Operational Research, 268(1), 128-147.

[20] De Giovanni, P. (2019). An optimal control model with defective products and goodwill damages. Annals of Operations Research, 1-12. 
[21] De Giovanni, P. (2016a). Coordination in a distribution channel with decisions on the nature of incentives and share-dependency on pricing. Journal of the Operational Research Society, 67(8), 1034-1049.

[22] De Giovanni, P. (2016b). Supply chain coordination: a multi-sector comparative case study analysis. Rome (Italy), Aracne.

[23] De Giovanni, P., \& Roselli, M. (2012). Overcoming the drawbacks of a revenue-sharing contract through a support program. Annals of Operations Research, 196(1), 201-222.

[24] De Giovanni, P. (2017). Closed-loop supply chain coordination through incentives with asymmetric information. Annals of Operations Research, 253(1), 133-167.

[25] De Giovanni, P., Karray, S., \& Martín-Herrán, G. (2019). Vendor Management Inventory with consignment contracts and the benefits of cooperative advertising. European Journal of Operational Research, 272(2), 465-480.

[26] Desai P. \& Srinivasan, K. (1996). Aggregate Versus Product Specific Pricing: Implications for Franchise and Traditional Channels, Journal of Retailing, 72(4), 357-382.

[27] Desai, P., Koenigsberg, O. \& Purohit, D. (2004), Strategic Decentralization and Channel Coordination, Quantitative Marketing and Economics, 2(1), 5-22.

[28] Dockner, E. J., Jorgensen, S., Van Long, N., \& Sorger, G. (2000). Differential games in economics and management science. Cambridge University Press.

[29] Dong, Y., \& Xu, K. (2002). A supply chain model of vendor managed inventory. Transportation Research Part E: Logistics and Transportation Review, 38(2), 75-95.

[30] El Ouardighi, F., Jørgensen, S., \& Pasin, F. (2008). A dynamic game of operations and marketing management in a supply chain. International Game Theory Review, 10(4), 373-397.

[31] He, X., Prasad, A., \& Sethi, S. P. (2009). Cooperative advertising and pricing in a dynamic stochastic supply chain: Feedback Stackelberg strategies. Production and Operations Management, 18, 78-94.

[32] Huang, Z., \& Li., S.X. (2001). Co-op advertising models in manufacturer-retailer supply chains: A game theory approach. European Journal of Operational Research, 135(3), 527-544.

[33] Hung, J. S., Fun, Y. P., \& Li, C. C. (1995). Inventory management in the consignment system. Production and Inventory Management Journal, 36(4), 1.

[34] Jørgensen, S. (1986). Optimal production, purchasing and pricing: A differential game approach. European Journal of Operational Research, 24(1), 64-76.

[35] Jørgensen, S., Sigué, S.P., \& Zaccour, G. (2000). Dynamic cooperative advertising in a marketing channel. Journal of Retailing, 76, 71-92. 
[36] Jørgensen, S., Taboubi, S., Zaccour, G. (2003). Retail promotions with negative brand image effects: Is cooperation possible? European Journal of Operational Research, 150, 395-405.

[37] Jørgensen, S., \& Zaccour, G. (2014). A survey of game-theoretic models of cooperative advertising. European Journal of Operational Research, 237, 1-14.

[38] Karray, S. (2013). Periodicity of pricing and marketing efforts in a distribution channel. European Journal of Operational Research, 228, 635-647.

[39] Karray, S. (2015). Cooperative promotions in the distribution channel. Omega, The International Journal of Management Science, 51, 49-58.

[40] Karray, S.,Martín-Herrán, G., \& Zaccour, G. (2017). Assessing the profitability of cooperative advertising programs in competing channels. International Journal of Production Economics, 187, 142-158.

[41] Karray, S., Martin-Herran, G., \& Sigué, S. P. (2017). Cooperative advertising for competing manufacturers: The impact of long-term promotional effects. International Journal of Production Economics, 184, 21-32.

[42] Karray, S., \& Zaccour, G. (2006). Could co-op advertising be a manufacturer's counterstrategy to store brands? Journal of Business Research, 59(9), 1008-1015.

[43] Karray, S., \& Zaccour, G. (2005). A differential game of advertising for national and store brands. In A. Haurie \& G. Zaccour (Eds.), Dynamic games: Theory and applications (pp. 213-230). Berlin: Springer.

[44] Kaya, O. (2010). Incentive and production decisions for remanufacturing operations. European Journal of Operational Research, 201(2), 442-453.

[45] Kogan, K., \& Tapiero, C. S. (2007). Supply chain games: operations management and risk valuation (Vol. 113). Springer Science \& Business Media.

[46] Li, S. X., Huang, Z., Zhu, J., \& Chau, P. Y. (2002). Cooperative advertising, game theory and manufacturer-retailer supply chains. Omega, The International Journal of Management Science, 30(5), 347-357.

[47] Li, S., \& Hua, Z. (2008). A note on channel performance under consignment contract with revenue-sharing. European Journal of Operational Research, 184(2), 793-796.

[48] Li, S., Zhu, Z., \& Huang, L. (2009). Supply chain coordination and decision making under consignment contract with revenue-sharing. International Journal of Production Economics, 120(1), 88-99.

[49] Liu, B., Cai, G., \& Tsay, A. (2014). Advertising in asymmetric competing supply chains. Production and Operations Management, 23(11), 1845-1858.

[50] Martín-Herrán, G., \& Sigué, S. P. (2017). An integrative framework of cooperative advertising: Should manufacturers continuously support retailer advertising? Journal of Business Research, 70, 67-73. 
[51] Nerlove, M., \& Arrow, K. J. (1962). Optimal advertising policy under dynamic conditions. Economica, 29, 129-142.

[52] Preeker, T., \& De Giovanni, P. (2018). Coordinating innovation projects with high tech suppliers through contracts. Research Policy, 47(6), 1161-1172.

[53] Ru, J., \& Wang, Y. (2010). Consignment contracting: Who should control inventory in the supply chain? European Journal of Operational Research, 201(3), 760-769.

[54] Ramani, V., \& De Giovanni, P. (2017). A two-period model of product cannibalization in an atypical Closed-loop Supply Chain with endogenous returns: The case of DellReconnect. European Journal of Operational Research, 262(3), 1009-1027.

[55] Sacco, A., \& De Giovanni, P. (2019). Channel coordination with a manufacturer controlling the price and the effect of competition. Journal of Business Research, 96, 97-114.

[56] Wang, Y., Jiang, L., \& Shen, Z. J. (2004). Channel performance under consignment contract with revenue-sharing. Management Science, 50(1), 34-47.

[57] Xiao, T., \& Jin, J. (2011). Coordination of a fashion apparel supply chain under lead-time-dependent demand uncertainty. Production Planning and Control, 22(3), 257-268.

[58] Xie, J., \& Ai, S. (2006). A note on Cooperative advertising, game theory and manufacturer-retailer supply chains. Omega, The International Journal of Management Science, 34 (5), 501-504.

[59] Yang, J., Xie, J., Deng, X., \& Xiong, H. (2013). Cooperative advertising in a distribution channel with fairness concerns. European Journal of Operational Research, 227(2), 401-407.

[60] Yue, J., Austin, J., Wang, M., \& Huang, Z. (2006). Coordination of cooperative advertising in a two-level supply chain when manufacturer offers discount. European Journal of Operational Research, 168(1), 65-85.

[61] Zha, Y., Zhang, J., Yue, X., \& Hua, Z. (2015). Service supply chain coordination with platform effort-induced demand. Annals of Operations Research, 235(1), 785-806. 